\title{
CUB Domain-containing Protein 1 (CDCP1) Is Down-regulated by Active Hexose-correlated Compound in Human Pancreatic Cancer Cells
}

\author{
KEISUKE KUHARA ${ }^{1,2}$, KAZUHIRO TOKUDA $^{3}$, TAKAO KITAGAWA ${ }^{4}$, BYRON BARON $^{5}$, \\ MASAYUKI TOKUNAGA ${ }^{4}$, KOJI HARADA ${ }^{6}$, MASARU TERASAKI ${ }^{2}$, OSAMU UEHARA $^{2}$, \\ TOHRU OHTA ${ }^{7}$, RIE TAKAI ${ }^{7}$, JUN-ICHI HAMADA $^{2}$, MASANOBU KOBAYASHI ${ }^{2}$, \\ TSUYOSHI SHIMO ${ }^{1}$, HIROKI NAGAYASU $^{1}$, YASUHIRO KURAMITSU $^{2}$ \\ ${ }^{1}$ Division of Oral and Maxillofacial Surgery, Department of Human Biology and Pathophysiology, \\ School of Dentistry, Health Sciences University of Hokkaido, Ishikari-Tobetsu, Japan; \\ ${ }^{2}$ Research Institute of Cancer Prevention, and ${ }^{7}$ Research Institute of Health Sciences, \\ Health Sciences University of Hokkaido, Ishikari-Tobetsu, Japan; \\ Departments of ${ }^{3}$ Ophthalmology, ${ }^{4}$ Biochemistry and Functional Proteomics, and \\ ${ }^{6}$ Oral and Maxillofacial Surgery, Yamaguchi University Graduate School of Medicine, Ube, Japan; \\ ${ }^{5}$ Centre for Molecular Medicine and Biobanking, \\ Faculty of Medicine and Surgery, University of Malta, Msida, Malta
}

\begin{abstract}
Background/Aim: We have previously reported that treatment of pancreatic cancer cells with active hexosecorrelated compound (AHCC), an extract of a basidiomycete mushroom, decreases the levels of tumor-associated proteins including heat-shock protein 27 (HSP27), heat shock factor 1 (HSF1) and sex-determining region Y-box 2 (SOX2). The transmembrane glycoprotein, $C U B$ domain-containing protein 1 (CDCP1) has been reported to be up-regulated in various cancers, and be associated with invasion and metastasis. The aim of this study was to examine the effect of AHCC on the expression of CDCP1 in KLM1-R cells. Materials and Methods: Gemcitabine-resistant pancreatic cancer cells (KLM1-R) were treated with AHCC $(10 \mathrm{mg} / \mathrm{ml})$ for $48 \mathrm{~h}$. Western blot analysis of cell extracts with anti-CDCP1 or antiactin antibodies was performed to assess the expression of CDCP1. Results: Expression of CDCP1 was reduced by AHCC treatment of KLM1-R cells, whereas expression of actin was not affected. The ratio of intensities of CDCPI/actin in AHCCtreated KLM1-R cells was significantly suppressed $(p<0.05)$ compared to untreated cells. Conclusion: AHCC down-
\end{abstract}

Correspondence to: Yasuhiro Kuramitsu, MD, Ph.D., Institute of Cancer Prevention, Health Sciences University of Hokkaido, 1757 Kanazawa, Ishikari-Tobetsu, Hokkaido 061-0293, Japan. Tel: +81 133231630, Fax: +81 133231782, e-mail: climates@hoku-iryou.ac.jp

Key Words: CDCP1, AHCC, pancreatic cancer, metastasis. regulated CDCP1 expression and inhibited the malignant progression of pancreatic cancer cells.

Although molecular diagnostics and therapeutics for various cancers have been developed, pancreatic cancer still shows a poor prognosis (a 5-year survival rate of less than 5\%). This very poor prognosis arises from its aggressiveness and lack of early diagnosis and effective therapies (1). At present, gemcitabine is clinically the most effective chemotherapeutic drug for pancreatic cancer (2). However, the median survival time of patients treated with gemcitabine is only half a year (3). Therefore, novel effective therapeutic agents for pancreatic cancer have to be developed.

Active hexose-correlated compound (AHCC) is derived from the basidiomycete mushroom Lentinula edodes. AHCC is composed of polysaccharides, amino acids, minerals and lipids enriched in $\alpha$ 1,4-glucans. So far AHCC has been reported to have immunomodulatory, anti-tumor, and antistress effects in vivo (4-6). We have previously investigated the direct effect of AHCC on cancer cells in vitro. The results showed that in vitro AHCC-treatment of KLM1-R cells down-regulated HSP 27, HSF1, and SOX2 (7-9). Our previous studies have shown that HSP27 is strongly related with gemcitabine-resistance in pancreatic cancer cells (1013). Also, we have shown that SOX2, which has been reported to prompt migration and invasion $(14,15)$, was overexpressed in malignant progressive fibrosarcoma clone cells compared to parental regressive clone cells (16). These results suggested that AHCC suppresses the factors 
associated with chemo-resistance and malignant progression. In addition, they suggested that AHCC down-regulates other proteins which play important roles in tumor malignant progression. In this study the effect of AHCC-treatment on the expression of CUB domain-containing protein 1 (CDCP1) was examined.

CDCP1 is a transmembrane glycoprotein that has been reported to be highly expressed in various cancers, and to be associated with prognosis, invasion, metastasis and anoikisresistance in cancer cells (17-23).

In this study, the effects of in vitro treatment of AHCC on the expression of CDCP1 were examined in KLM1-R cells by using western blotting.

\section{Materials and Methods}

Cancer cell line and conditions. The KLM1-R pancreatic cancer cell line is gemcitabine-resistant. It has been established at the Department of Surgery and Science, Kyushu University Graduate School of Medical Science and derived from the gemcitabinesensitive pancreatic cancer cell line KLM1, that was exposed to gemcitabine. The cells were kept in RPMI-1640 medium supplemented with $10 \%$ fetal bovine serum (inactivated at $56^{\circ} \mathrm{C}$ for $30 \mathrm{~min}$ ), $2 \mathrm{mM} \mathrm{L}$-glutamine, $1.5 \mathrm{~g} / \mathrm{l}$ sodium bicarbonate, $10 \mathrm{mM} \mathrm{N}$ 2-hydroxyehylpiperazine- $N$ '-2-ethanesulfonic acid (HEPES), and $1.0 \mathrm{mM}$ sodium pyruvate, in a $\mathrm{CO}_{2}$ incubator.

Agents. AHCC was kindly provided by the Amino Up Chemical Co., Ltd. (Sapporo, Japan), and it was dissolved in RPMI-1640 medium and filter-sterilized before in vitro use.

Sample preparation. The KLM1-R cells were incubated for $48 \mathrm{~h}$ with or without AHCC $(10 \mathrm{mg} / \mathrm{ml})$. Then the cells were homogenized in icecold lysis buffer [50 mM Tris-HCl, pH 7.5, $165 \mathrm{mM}$ sodium chloride, $10 \mathrm{mM}$ sodium fluoride, $1 \mathrm{mM}$ sodium vanadate, $1 \mathrm{mM}$ phenyl methyl sulfonyl fluoride, $10 \mathrm{mM}$ ethylendiaminetetra-acetic acid, $10 \mu \mathrm{g} / \mathrm{ml}$ aprotinin, $10 \mu \mathrm{g} / \mathrm{ml}$ leupeptin, and $1 \%$ nonylphenocypolyehoxylethanol40], and centrifuged at $15,000 \times g$ for $30 \mathrm{~min}$ at $4^{\circ} \mathrm{C}$. The supernatant was collected and used for further experiments.

Western blot analysis. Fifteen $\mu \mathrm{g}$ of protein were used in western blot analysis. Pre-cast gels (4-20\% gradient polyacrylamide gels; MiniPROTEAN TGX Gels, Bio-Rad, Hercules, CA, USA) were used for sodium dodecylsulphate-polyacrylamide gel electrophoresis (SDSPAGE). The separated protein bands were transferred onto polyvinylidene difluoride membranes (Immobilon-P; Millipore, Bedford, MA, USA). Blocking was done with Tris-buffered saline (TBS) containing 5\% skimmed milk for $1 \mathrm{~h}$ at room temperature. The primary antibodies used were: rabbit monoclonal antibody against CDCP1 (\#4115 1:1,000, CST, Beverly, MA, USA) and goat polyclonal antibody against actin (1:200, Santa Cruz Biotechnology, Inc., Santa Cruz, CA, USA). Membranes were incubated with each primary antibody overnight at $4^{\circ} \mathrm{C}$, and after washing three times with TBS containing $0.05 \%$ Tween-20, were further incubated with secondary antibodies conjugated with horseradish peroxidase (Jackson Immuno Research Laboratories Inc., West Grove, PA, USA) for $1 \mathrm{~h}$. Bands of CDCP1 and actin were visualized by an enhanced chemiluminescence system (ImmunoStar Long Detection; Wako,
Osaka, Japan) and LAS-1000 Pro (Fujifilm Corporation, Tokyo, Japan). Intensities of bands of CDCP1 and actin were quantified by using the Multi Gauge ver. 3.0 software (Fujifilm Corporation).

The ratio of intensity of CDCP1 to actin in AHCC-treated or untreated KLM1R cells from two independent experiments were calculated.

\section{Results}

Since CDCP1 has been reported to be over-expressed in many types of cancers and be associated with invasion and metastasis, the effect of AHCC on the expression of CDCP1 in KLM1-R cells treated with or without AHCC was examined by western blot analysis. AHCC-treatment suppressed the expression of CDCP1, but did not suppress the levels of actin (Figure 1). The ratio of intensities of CDCP1/actin in KLM1-R cells treated with or without AHCC $(10 \mathrm{mg} / \mathrm{ml})$ were $1.442 \pm 0.791$ and $3.148 \pm 2.260$, respectively. The $p$-value of CDCP1/actin between AHCCtreated and untreated KLM1-R cells was $0.037 \quad(p<0.05)$ (Figure 2).

\section{Discussion}

The present study showed that AHCC down-regulated the expression of CDCP1 in gemcitabine-resistant pancreatic cancer KLM1-R cells, but it did not affect actin levels.

CDCP1 is a transmembrane glycoprotein which has been reported to be up-regulated in many kinds of cancer tissues and cells (24-26). It has been suggested that CDCP1 plays important roles in cancer invasion and metastasis $(21,27,28)$.

CDCP1 was shown to modulate cell-substratum adhesion and motility in colon cancer cell lines (29). Knockdown of CDCP1 in pancreatic cancer cells resulted in up-regulation of E-cadherin and down-regulation of $\mathrm{N}$-cadherin, indicating that CDCP1 suppresses the epithelial phonotype and increases mesenchymal phenotype in cancer cells (30). Furthermore, it has been shown that CDCP1 functions as an essential regulator of MT1-MMP-mediated invasion and invadopodia-mediated invasion of cancer cells (31).

Some groups reported the relationship between CDCP1 and prognosis of cancer patients. Glioblastoma is one of the most aggressive tumors among the malignant brain tumors showing strong invasiveness, recurrence and very poor prognosis. Varghese et al. reported that the expression of some survival kinase genes including CDCP1 was associated with recurrencerelated prognosis (32). He et al. reported that an increased CDCP1 expression was correlated with poor disease-free and overall survival in patients with ovarian clear cell carcinoma (33). Chou et al. identified CDCP1 as a useful prognostic factor for patients with colorectal cancer (34). Based on these reports, it is concluded that it is very important to regulate CDCP1 for the treatment of aggressive cancer cells. 
70 kDa

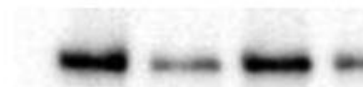

CDCP1

43 kDa

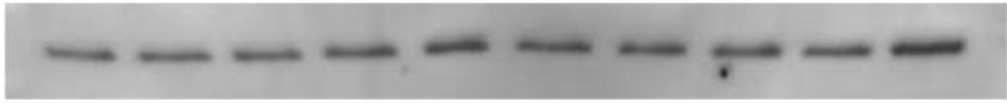

Actin

AHCC (10mg/ml)

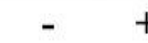

70 kDa

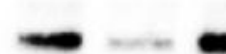

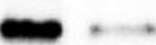

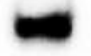

$+\cdots$

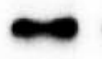

$-$

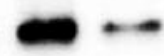

CDCP1

\section{3 kDa}

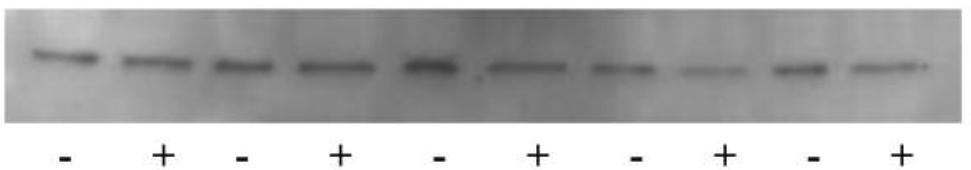

Actin

AHCC (10mg/ml)

Figure 1. Western blot analysis of CDCP1 and actin in active hexose correlated compound (AHCC) treated $(10 \mathrm{mg} / \mathrm{ml}) \mathrm{or} \mathrm{untreated}(0 \mathrm{mg} / \mathrm{ml})$ pancreatic cancer KLM1-R cells. The protein expression of CDCP1 (bands of $70 \mathrm{kDa}$ ) was reduced by AHCC-treatment in KLM1-R cells compared to control untreated KLM1-R cells. On the other hand, protein expression of actin (bands of $43 \mathrm{kDa}$ ) did not change significantly.

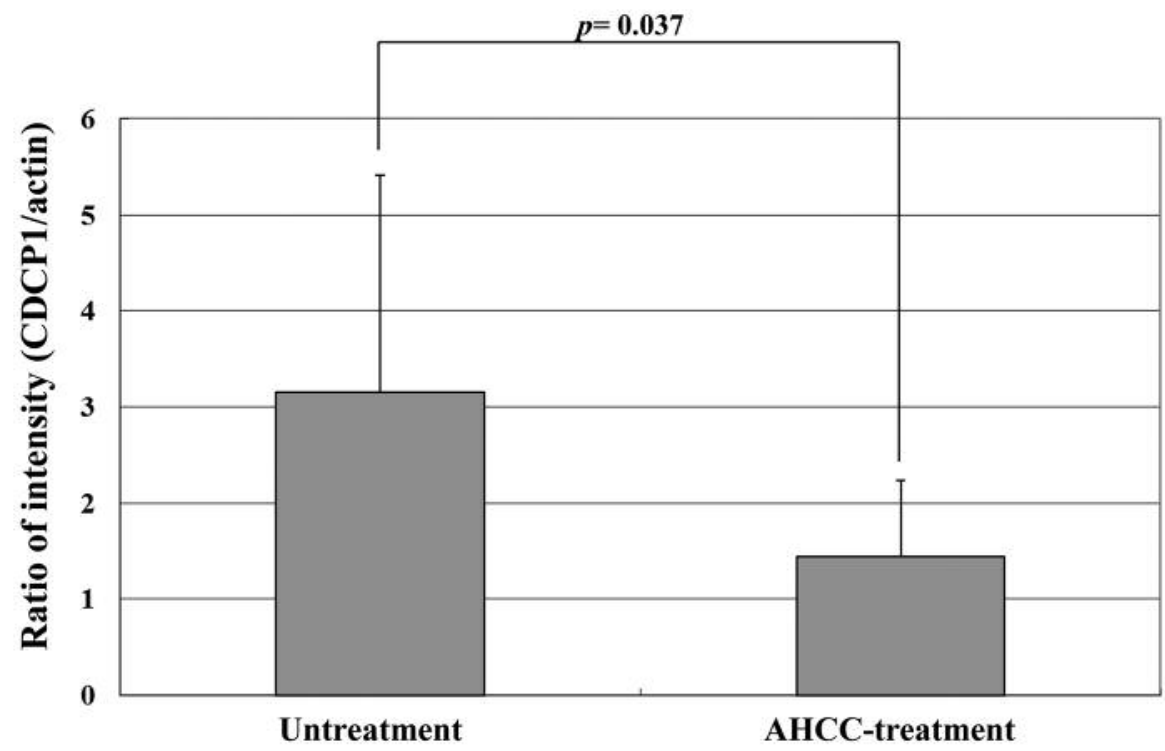

Figure 2. The ratio of the intensities of the CDCP1/actin bands in KLM1-R cells. This graph shows the ratio of the intensities of CDCP1 protein to actin protein bands in AHCC-treated or untreated KLM1-R cells. The ratio of CDCP1/actin in KLM1-R cells was significantly reduced by AHCC treatment in vitro $(p<0.05$ by the Student's $t$-test $)$. A value of $p<0.05$ was considered statistically significant $(n=10)$.

Chemo-resistance of cancer cells is a troubling issue in the treatment of cancer patients. In our studies aimed to identify key molecules playing important role on the induction of gemcitabine-resistance, HSP27 was shown to be an important protein involved in gemcitabine-resistance (10-13). However, to find out additional molecules related to chemo- resistance still need to be identified. Sandercock et al. reported that anti-CDCP1 antibody significantly enhanced the efficacy of cisplatin in a patient-derived non-small cell lung cancer xenograft model (35). Alajati et al. reported that CDCP1 is related not only to chemo-resistance, but also to trastuzumab resistance. They showed that CDCP1 bound to 
HER2 through its intracellular domain and increased HER2 interaction with the non-receptor tyrosine kinase c-SRC led to trastuzumab resistance (36). From these reports and our recent studies, it is suggested that AHCC can be used against chemo-resistance and molecular-targeted agent-resistance cancers, since AHCC suppresses both HSP27 and CDCP1.

Several groups suggested CDCP1 as a target for cancer therapy. Harrington et al. showed that in vitro silencing of CDCP1 suppressed migration and non-adherent cell growth of high-grade serous ovarian cancer cells. Furthermore, in patient-derived xenograft mouse models, blocking CDCP1 with antibodies resulted in effective suppression of tumor growth (37). In vitro and in vivo experiments using RG7287, an activating anti-CDCP1 antibody, also suggested CDCP1 as a therapeutic target on cancer cells. The treatment with RG7287 resulted in down-regulation of CDCP1 in cancer cells in vitro, and significant tumor growth inhibition in vivo (38).

How does AHCC suppresses the expression of CDCP1? It is not yet clear which molecule, acting upstream of CDCP1, is down-regulated by AHCC. Chiu et al. reported that ADAM9 enhanced the expression of CDCP1 by suppressing miR-218 in lung cancer cells (39). In addition, Cao et al. reported that CDCP1 was regulated by HIF- $2 \alpha$ at mRNA and protein levels in HCC cell lines (40). Unfortunately, we could not show down-regulation of ADAM9 or HIF- $2 \alpha$ in cancer cells by in vitro treatment with AHCC (data not shown).

Although the mechanism that mediates down-regulation of CDCP1 by AHCC is not clear, AHCC is suggested as a possible candidate for treating progressive pancreatic cancer.

\section{Conflicts of Interest}

The Authors declared no potential conflicts of interest with respect to the research, authorship, and/or publication of this article.

\section{Acknowledgements}

The Authors would like to thank Dr. Shin-ichiro Maehara and Prof. Yoshihiko Maehara at Kyushu University for providing KLM1-R cells. This work was supported in part by Grants-in-Aid from the Ministry of Education, Science, Sports, and Culture of Japan (no. 17K07218 to Yasuhiro Kuramitsu). Immunoblot detection by LAS1000 was performed at Gene Research Center of Yamaguchi University.

\section{References}

1 Murr MM, Sarr MG, Oishi AJ and van Heerden JA: Pancreatic cancer. CA Cancer J Clin 44: 304-318, 1994.

2 Burris HA, Moore MJ III, Andersen J, Green MR, Rothenberg ML, Modiano MR, Cripps MC, Portenoy RK, Storniolo AM, Tarassoff P, Nelson R, Dorr FA, Stephens CD and von Hoff DD: Improvements in survival and clinical benefit with gemcitabine as first-line therapy for patients with advanced pancreas cancer: a randomized trial. J Clin Oncol 15: 2403-2413, 1997.
3 Carmichael J, Fink U, Russell RC, Spittle MF, Harris AL, Spiessi G and Blatter J: Phase II study of gemcitabine in patients with advanced pancreatic cancer. Br J Cancer 73: 101-105, 1996.

4 Ritz BW: Supplementation with active hexose correlated compound increases survival following infectious challenge in mice. Nutr Rev 66: 526-531, 2008.

5 Kidd PM: The use of mushroom glucans and proteoglycans in cancer treatment. Altern Med Rev 5: 4-27, 2000.

6 Ye SF, Ichimura K, Wakame K and Ohe M: Suppressive effects of Active Hexose Correlated Compound on the increased activity of hepatic and renal ornithine decarboxylase induced by oxidative stress. Life Sci 74: 593-602, 2003.

7 Suenaga S, Kuramitsu Y, Kaino S, Maehara S, Maehara Y, Sakaida I and Nakamura K: Active hexose-correlated compound down-regulates HSP27 of pancreatic cancer cells, and helps the cytotoxic effect of gemcitabine. Anticancer Res 34: 141-146, 2014.

8 Nawata J, Kuramitsu Y, Wang Y, Kitagawa T, Tokuda K, Baron B, Akada J, Suenaga S, Kaino S, Maehara S, Maehara Y, Sakaida I and Nakamura K: Active hexose-correlated compound down-regulates sex-determining region Y-box 2 of pancreatic cancer cells. Anticancer Res 34: 4807-4811, 2014.

9 Tokunaga M, Baron B, Kitagawa T, Tokuda K and Kuramitsu Y: Active hexose-correlated compound down-regulates heat shock factor 1, a transcription factor for HSP27, in gemcitabineresistant human pancreatic cancer cells. Anticancer Res 35: 6063-6067, 2015.

10 Mori-Iwamoto S, Kuramitsu Y, Ryozawa S, Taba K, Fujimoto M, Okita K, Nakamura K and Sakaida I: A proteomic profiling of gemcitabine resistance in pancreatic cancer cell lines. Mol Med Rep 1: 429-434, 2008.

11 Mori-Iwamoto S, Kuramitsu Y, Ryozawa S, Mikuria K, Fujimoto M, Maehara SI, Maehara Y, Okita K, Nakamura K and Sakaida I: Proteomics finding heat shock protein 27 as a biomarker for resistance of pancreatic cancer cells to gemcitabine. Int J Oncol 31: 1345-1350, 2007.

12 Taba K, Kuramitsu Y, Ryozawa S, Yoshida K, Tanaka T, MoriIwamoto S, Maehara S, Maehara Y, Sakaida I and Nakamura K: KNK437 downregulates heat shock protein 27 of pancreatic cancer cells and enhances the cytotoxic effect of gemcitabine. Chemotherapy 57: 12-16, 2011.

13 Mori-Iwamoto S, Taba K, Kuramitsu Y, Ryozawa S, Tanaka T, Maehara S, Maehara Y, Okita K, Nakamura K and Sakaida I: Interferon-gamma down-regulates heat shock protein 27 of pancreatic cancer cells and helps in the cytotoxic effect of gemcitabine. Pancreas 38: 224-226, 2009.

14 Lou X, Han X, Jin C, Tian W, Yu W, Ding D, Cheng L, Huang $\mathrm{B}$, Jiang $\mathrm{H}$ and Lin B: SOX2 targets fibronectin 1 to promote cell migration and invasion in ovarian cancer: new molecular leads for therapeutic intervention. OMICS 17: 510-518, 2013.

15 Chou YT, Lee CC, Hsiao SH, Lin SE, Lin SC, Chung CH, Chung CH, Kao YR, Wang YH, Chen CT, Wei YH and Wu CW: The emerging role of SOX2 in cell proliferation and survival and its crosstalk with oncogenic signaling in lung cancer. Stem Cells 31: 2607-2619, 2013.

16 Kuramitsu Y, Tanaka I, Wang Y, Okada F, Tokuda K, Kitagawa $\mathrm{T}$, Akada $\mathrm{J}$ and Nakamura K: Inflammation-related tumor progression in murine fibrosarcoma exhibited over-expression of sex-determining region Y-box 2 (Sox2) compared to parental regressor cells. Anticancer Res 35: 3217-3221, 2015. 
17 Leroy C, Shen Q, Strande V, Meyer R, McLaughlin ME, Lezan E, Bentires-Alj M, Voshol H, Bonenfant D and Alex Gaither L: CUB-domain-containing protein 1 overexpression in solid cancers promotes cancer cell growth by activating Src family kinases. Oncogene 34: 5593-5598, 2015.

18 Ikeda J, Oda T, Inoue M, Uekita T, Sakai R, Okumura M, Aozasa $\mathrm{K}$ and Morii E: Expression of CUB domain containing protein (CDCP1) is correlated with prognosis and survival of patients with adenocarcinoma of lung. Cancer Sci 100: 429-433, 2009.

19 Uekita T, Jia L, Narisawa-Saito M, Yokota J, Kiyono T and Sakai R: CUB domain-containing protein 1 is a novel regulator of anoikis resistance in lung adenocarcinoma. Mol Cell Biol 27: 7649-7660, 2007.

20 Perry SE, Robinson P, Melcher A, Quirke P, Bühring HJ, Cook GP and Blair GE: Expression of the CUB domain containing protein 1 (CDCP1) gene in colorectal tumour cells. FEBS Lett 58: 1137-1142, 2007.

21 Liu H, Ong SE, Badu-Nkansah K, Schindler J, White FM and Hynes RO: CUB-domain-containing protein 1 (CDCP1) activates Src to promote melanoma metastasis. Proc Natl Acad Sci USA 108: 1379-1384, 2011

22 Uekita T, Tanaka M, Takigahira M, Miyazawa Y, Nakanishi Y, Kanai Y, Yanagihara K and Sakai R: CUB-domain-containing protein 1 regulates peritoneal dissemination of gastric scirrhous carcinoma. Am J Pathol 172: 1729-1739, 2008.

23 Miyazawa Y, Uekita T, Hiraoka N, Fujii S, Kosuge T, Kanai Y, Nojima $Y$ and Sakai R: CUB domain-containing protein 1, a prognostic factor for human pancreatic cancers, promotes cell migration and extracellular matrix degradation. Cancer Res 70: 5136-5146, 2010.

24 Scherl-Mostageer M, Sommergruber W, Abseher R, Hauptmann $\mathrm{R}$, Ambros $\mathrm{P}$ and Schweifer N: Identification of a novel gene, $\mathrm{CDCP} 1$, overexpressed in human colorectal cancer. Oncogene 20: 4402-4408, 2001

25 Yang L, Dutta SM, Troyer DA, Lin JB, Lance RA, Nyalwidhe JO, Drake RR and Semmes OJ: Dysregulated expression of cell surface glycoprotein CDCP1 in prostate cancer. Oncotarget 6: 43743-43758, 2015.

26 Wortmann A, He Y, Deryugina EI, Quigley JP and Hooper JD: The cell surface glycoprotein CDCP1 in cancer--insights, opportunities, and challenges. IUBMB Life 61: 723-730, 2009.

27 Nakashima K, Uekita T, Yano S, Kikuchi JI, Nakanishi R, Sakamoto N, Fukumoto K, Nomoto A, Kawamoto K, Shibahara $\mathrm{T}$, Yamaguchi $\mathrm{H}$ and Sakai R: Novel small molecule inhibiting CDCP1-PKC $\delta$ pathway reduces tumor metastasis and proliferation. Cancer Sci 108: 1049-1057, 2017.

28 Uekita T, Fujii S, Miyazawa Y, Iwakawa R, Narisawa-Saito M, Nakashima K, Tsuta K, Tsuda H, Kiyono T, Yokota J and Sakai R: Oncogenic Ras/ERK signaling activates CDCP1 to promote tumor invasion and metastasis. Mol Cancer Res 12: 1449-1459, 2014.

29 Orchard-Webb DJ, Lee TC, Cook GP and Blair GE: CUB domain containing protein 1 (CDCP1) modulates adhesion and motility in colon cancer cells. BMC Cancer 14: 754, 2014.

30 Miura S, Hamada S, Masamune A, Satoh K and Shimosegawa T: CUB-domain containing protein 1 represses the epithelial phenotype of pancreatic cancer cells. Exp Cell Res 321: 209218,2014
31 Miyazawa Y, Uekita T, Ito Y, Seiki M, Yamaguchi H and Sakai R: CDCP1 regulates the function of MT1-MMP and invadopodia-mediated invasion of cancer cells. Mol Cancer Res 11: 628-637, 2013.

32 Varghese RT, Liang Y, Guan T, Franck CT, Kelly DF and Sheng Z: Survival kinase genes present prognostic significance in glioblastoma. Oncotarget 7: 20140-20151, 2016.

$33 \mathrm{He}$ Y, Wu AC, Harrington BS, Davies CM, Wallace SJ, Adams MN, Palmer JS, Roche DK, Hollier BG, Westbrook TF, Hamidi H, Konecny GE, Winterhoff B, Chetty NP, Crandon AJ, Oliveira NB, Shannon CM, Tinker AV, Gilks CB, Coward JI, Lumley JW, Perrin LC, Armes JE and Hooper JD: Elevated CDCP1 predicts poor patient outcome and mediates ovarian clear cell carcinoma by promoting tumor spheroid formation, cell migration and chemoresistance. Oncogene 35: 468-478, 2016.

34 Chou CT, Li YJ, Chang CC, Yang CN, Li PS, Jeng YM, Chen ST, Kuo ML, Lin IC and Lin BR: Prognostic Significance of CDCP1 Expression in Colorectal Cancer and Effect of Its Inhibition on Invasion and Migration. Ann Surg Oncol 22: 43354343, 2015.

35 Sandercock AM, Rust S, Guillard S, Sachsenmeier KF, Holoweckyj N, Hay C, Flynn M, Huang Q, Yan K, Herpers B, Price LS, Soden J, Freeth J, Jermutus L, Hollingsworth R and Minter R: Identification of anti-tumour biologics using primary tumour models, 3-D phenotypic screening and image-based multi-parametric profiling. Mol Cancer 14: 147, 2015.

36 Alajati A, Guccini I, Pinton S, Garcia-Escudero R, Bernasocchi T, Sarti M, Montani E, Rinaldi A, Montemurro F, Catapano C, Bertoni $\mathrm{F}$ and Alimonti A: Interaction of CDCP1 with HER2 enhances HER2-driven tumorigenesis and promotes trastuzumab resistance in breast cancer. Cell Rep 11: 564-576, 2015.

37 Harrington BS, He Y, Davies CM, Wallace SJ, Adams MN, Beaven EA, Roche DK, Kennedy C, Chetty NP, Crandon AJ, Flatley C, Oliveira NB, Shannon CM, deFazio A, Tinker AV, Gilks CB, Gabrielli B, Brennan DJ, Coward JI, Armes JE, Perrin LC and Hooper JD: Cell line and patient-derived xenograft models reveal elevated CDCP1 as a target in high-grade serous ovarian cancer. Br J Cancer 114: 417-426, 2016.

38 Kollmorgen G, Niederfellner G, Lifke A, Spohn GJ, Rieder N, Harring SV, Bauss F, Burtscher H, Lammers R and Bossenmaier B: Antibody mediated CDCP1 degradation as mode of action for cancer targeted therapy. Mol Oncol 7: 1142-1151, 2013.

39 Chiu KL, Kuo TT, Kuok QY, Lin YS, Hua CH, Lin CY, Su PY, Lai LC and Sher YP: ADAM9 enhances CDCP1 protein expression by suppressing miR-218 for lung tumor metastasis. Sci Rep 5: 16426, 2015.

40 Cao M, Gao J, Zhou H, Huang J, You A, Guo Z, Fang F, Zhang $\mathrm{W}$, Song $\mathrm{T}$ and Zhang T: HIF- $2 \alpha$ regulates CDCP1 to promote PKC $\delta$-mediated migration in hepatocellular carcinoma. Tumour Biol 37: 1651-1662, 2016. 